\title{
El renacer del movimiento obrero después del Centenario: el ciclo de protestas obreras de 1911-1912, sus alcances y limitaciones
}

\author{
The rebirth of the labor movement after the Centennial: the cycle of workers' \\ protests of 1911-1912, its scope and limitations.
}

\author{
Alejandro Belkin \\ ambelkin@gmail.com \\ Instituto de Investigaciones en Humanidades y \\ Ciencias Sociales (UNLP) - CONICET / Universidad \\ de Buenos Aires / Centro de Estudios Históricos de los \\ de los trabajadores y las izquierdas, Argentina
}

Recepción: 03 Febrero 2021

Aprobación: 29 Abril 2021

Publicación: 01 Marzo 2022

Cita sugerida: Belkin, A. (2022). El renacer del movimiento obrero después del Centenario: el ciclo de protestas obreras de 1911-1912, sus alcances y limitaciones. Sociohistórica, 49, e161. https://doi.org/10.24215/18521606e161
Resumen: El ciclo de protestas obreras iniciado a comienzos del siglo XX, a partir de la huelga general de 1902, se extendió hasta 1910 y fue clausurado de manera violenta por la represión estatal y paraestatal. Las organizaciones obreras quedaron muy debilitadas. El proceso de recuperación fue lento. Sin embargo, hacia mayo de 1911 comenzó un proceso de creciente agitación obrera, que se profundizó en los meses siguientes. A comienzos de 1912, los ferrocarriles y el puerto se encontraban paralizados. Este ciclo de protestas obreras terminó en duras derrotas para los trabajadores. En este trabajo nos proponemos analizar los inicios, el desarrollo y el cierre de este ciclo de conflictividad gremial. Prestaremos especial atención a la estrategia desplegada por los sindicatos, los organismos estatales y las patronales involucradas. En la reconstrucción de estos sucesos hemos utilizado fuentes oficiales, diarios comerciales y periódicos gremiales y políticos de diversas orientaciones ideológicas.

Palabras clave: Anarquismo, Socialismo, Sindicalismo, Centenario, Huelgas.

\begin{abstract}
The cycle of worker protests that began at the beginning of the 20th century, starting with the general strike of 1902, lasted until 1910 and was violently closed by state and parastatal repression. The workers' organizations were very weakened. The recovery process was slow. However, towards May 1911 a process of growing worker unrest began, which deepened in the following months. At the beginning of 1912, the railways and the port were paralyzed. This cycle of worker protests ended in tough defeats for the workers. In this work we propose to analyze the beginnings, development and closure of this cycle of union conflict. We will pay special attention to the strategy deployed by the unions, state agencies and employers involved. In the reconstruction of these events we have used official sources, commercial newspapers and union and political newspapers of different ideological orientations.
\end{abstract}

Keywords: Anarchism, Socialism, Syndicalism, Centennial, Strikes. 
La historia del movimiento obrero argentino, entre fines del siglo XIX y comienzos del siglo XX, ha sido abordada por diversos autores y analizada desde distintas perspectivas (Barrancos, 1991; Bilsky, 1985; Godio, 1972; Poy, 2014; Suriano, 1988, 2000, 2001). Sin embargo, el período posterior, entre el Centenario y el primer gobierno de Yrigoyen, no ha recibido la misma atención. La historia de la clase trabajadora y sus organizaciones gremiales, en esos años, ha sido escasamente transitada, es un terreno cuasi yermo. En los trabajos clásicos son muy escasas las referencias a las huelgas y a la situación que atravesaban los gremios (Abad de Santillán, 1933; Iscaro, 1958; Marotta, 1961; Oddone, 1975). Más aún, aparece un hiato en la narración de los sucesos. El relato salta del Centenario hasta el $3^{\circ}$ Congreso de Unidad, realizado a fines de 1912, quedando en la oscuridad los años intermedios. Son exiguas las menciones a conflictos y a la condición en la que se encontraban las organizaciones obreras de aquella época. Sintomáticamente, Marotta es el único autor que menciona con algún detalle las huelgas y el estado de los gremios en esta etapa. El creciente protagonismo del sindicalismo revolucionario y la participación del propio autor en los sucesos que relata, quizás expliquen la mayor atención que recibe este período en su libro. Entre las producciones académicas, apenas contamos con un estudio de caso, un trabajo donde se analiza la huelga ferroviaria de 1912 (Suriano, 1991). También encontramos menciones a la huelga de los marítimos, acontecida en aquella época, en investigaciones más amplias sobre el sector (Adelman, 1993; Caruso, 2016). Sin embargo, estos conflictos fueron examinandos de manera aislada, sin insertarlos en el ciclo de luchas al que pertenecieron. La ausencia de (grandes) huelgas generales acaso explique la carencia de investigaciones específicas sobre este período. Los estudios sobre los trabajadores, sus organizaciones y sus luchas, cobran nueva relevancia a partir de 1916 (Ceruso, 2015; Garguin, 2000; Gordillo, 1988; Horowitz, 2015; Monserrat, 2011; Palermo, 2009). La llegada de Yrigoyen al poder, las complejas relaciones que tejió con las organizaciones sindicales y el inicio de un nuevo ciclo de huelgas, hizo que renazca el interés de los investigadores por el movimiento obrero. ${ }^{1}$ En definitiva, hasta el presente, no contamos con ningún trabajo que examine el estado de las organizaciones obreras y sus luchas entre los años 1910-1916. ${ }^{2}$ Con este trabajo intentamos aportar a la reconstrucción de este período clave de la historia argentina, prestando especial atención al movimiento gremial.

En noviembre de 1902 tuvo lugar en la Argentina la primera huelga general (Boido, 2002); este acontecimiento marcó un hito en la historia del movimiento obrero (Iñigo Carrera, 2000). A partir de este suceso, se inició un ciclo de creciente conflictividad gremial, que se extendió -con altibajos- hasta mayo de 1910 (Korzeniewicz, 1989, 1995). En vísperas del Centenario, la etapa de grandes huelgas fue clausurada de manera abrupta por la represión estatal y paraestatal (Barry, 2009; Belkin, 2020; Iñigo Carrera, 2013; Suriano, 2010). Un mes más tarde, el Congreso Nacional aprobó la Ley de Defensa Social, complementando y reforzando el cerrojo represivo (Costanzo, 2007). Las manifestaciones de protesta y las actividades gremiales quedaron drásticamente restringidas. Nunca antes el movimiento obrero había sufrido una derrota de tamañas dimensiones. La violencia estatal logró diezmar a las organizaciones proletarias. Los sindicatos fueron arrasados por la cólera reaccionaria y muchos fueron prácticamente desmantelados. Aquellos que lograron sobrevivir quedaron reducidos a pequeños núcleos de activistas. El movimiento obrero quedó extremadamente debilitado y a la defensiva. Ninguna represión previa había logrado horadar tan profundamente a las fuerzas proletarias. La derrota fue honda y generalizada. Las sociedades gremiales, construidas durante décadas de esforzada y paciente labor militante, fueron devastadas por las fuerzas represivas. Los militantes libertarios fueron especialmente castigados, sufriendo persecuciones, arrestos, torturas y deportaciones. El anarquismo, en consecuencia, fue amputado del movimiento obrero. La reacción estatal y paraestatal se ensañó con particular dureza contra la Federación Obrera Regional Argentina (FORA), emblema del movimiento ácrata, la cual quedó reducida a escombros y sobrevivió solo nominalmente.

La destrucción de las organizaciones gremiales y la ausencia forzosa de los militantes ácratas, generó novedosas oportunidades para las otras corrientes del movimiento obrero. Los sindicalistas advirtieron las 
posibilidades que brindaba ese singular contexto y se lanzaron a liderar el proceso de reconstrucción de las organizaciones obreras. Los socialistas también percibieron las potencialidades del nuevo contexto histórico. ${ }^{3}$ Sin embargo, sus vínculos con el movimiento obrero siempre fueron débiles y contradictorios. Su estrategia, centrada en la actividad electoral, dificultó su implantación en las organizaciones gremiales (Camarero, 2015; Tortti, 1989).

Una vez superado el peor momento de la represión, el movimiento obrero emprendió un lento y dificultoso proceso de regeneración. Ante un movimiento libertario diezmado por la represión y las dificultades del socialismo para insertarse en el mundo gremial, la corriente sindicalista fue la que se encontró mejor predispuesta para incidir en el proceso de reconstrucción de las organizaciones obreras. La Confederación Obrera Regional Argentina (CORA), central obrera hegemonizada por el sindicalismo revolucionario, logró subsistir y brindó su apoyo para la reorganización del movimiento obrero, convirtiéndose en una pieza clave en el campo proletario.

En este artículo analizamos el ciclo de luchas gremiales que comenzó en mayo de 1911 y se extendió hasta febrero de 1912. Es una etapa signada por huelgas sectoriales de grandes dimensiones que, en su gran mayoría, terminaron en duras derrotas para los trabajadores. En este periodo, el único gremio importante que se alzó con una victoria fue el de los ladrilleros. La sociedad obrera que los agrupaba fue organizada y conducida por el sindicalismo revolucionario, tuvo la particularidad de ser el único gremio que rechazó la mediación estatal, promovida por el Departamento Nacional del Trabajo (DNT). Para realizar la presente reconstrucción historiográfica hemos consultado una gran variedad de fuentes, publicaciones políticas, hojas gremiales, diarios comerciales y documentos oficiales.

\section{LOS CONFLICTOS}

En el año 1911 se registró la menor cantidad de huelgas desde que el DNT comenzó a contabilizarlas en 1907. Sin embargo, si consideramos el número de huelguistas, la situación cambia diametralmente, el año 1911 muestra un pico de conflictividad social, superando las marcas del trienio anterior. Por lo tanto, en el período en estudio, las luchas obreras son menores en número pero concentran una mayor cantidad de huelguistas. La debilidad de las organizaciones obreras y la feroz represión imperante en la época conminaban al proletariado a priorizar aquellos gremios con mayor cantidad de trabajadores, donde el número podía juegar a su favor. 


\section{Huelgas y huelguistas}

1907 - 1912

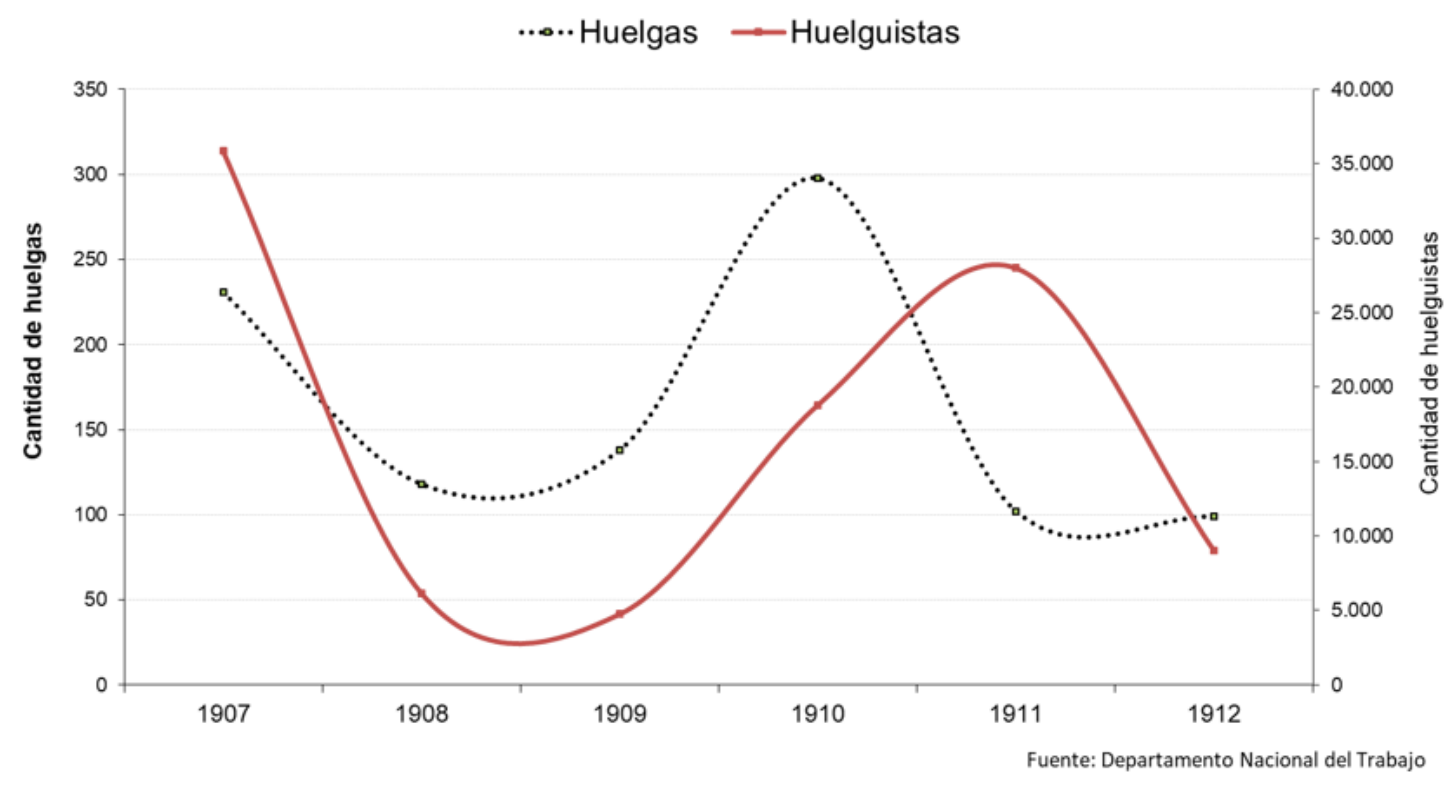

Un año después de ocurridos los sucesos del Centenario, en mayo de 1911, el retroceso del movimiento obrero comenzó a revertirse. Desde ese momento se ingresa en una nueva fase expansiva de la conflictividad gremial. Las huelgas se multiplican a medida que avanza el año. Dos tercios de las medidas de fuerza comenzaron en el segundo semestre. El $36 \%$ de las huelgas estallaron en el último trimestre. Ese período concentra la mitad de los huelguistas de todo el año, 13.322 (48\%).

\section{Huelgas en la Capital Federal \\ 1911 - 1912}

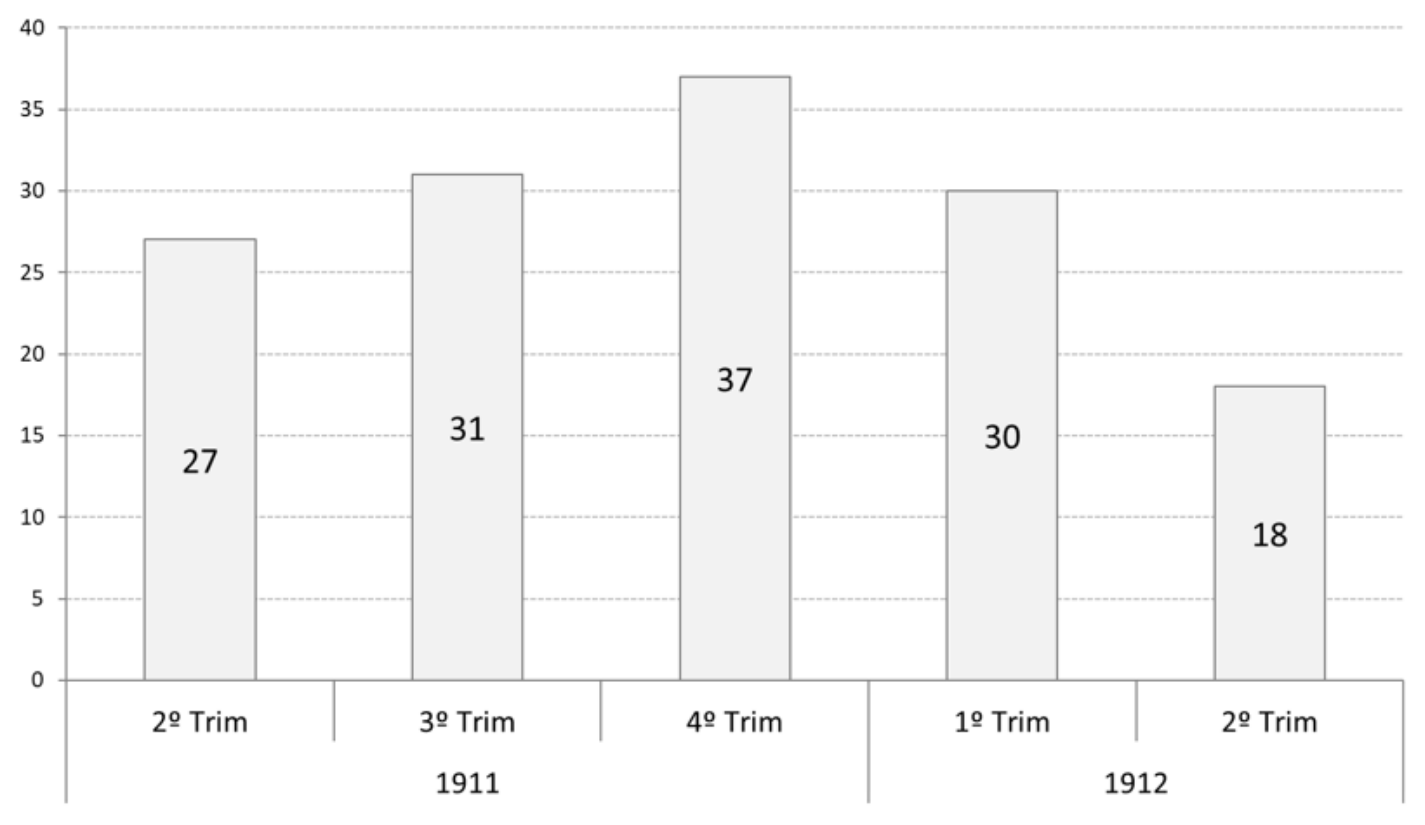


El ciclo huelguístico se extendió hasta los primeros meses del año siguiente. Según las estadísticas oficiales, en 1912 se registraron 99 huelgas. Su distribución por trimestres muestra picos de conflictividad en el primero y último tramo del año. Sin embargo, si consideramos la cantidad de huelguistas, el panorama cambia drásticamente. El 70 \% corresponden al primer trimestre del año. La conflictividad laboral se desploma en el segundo y tercer trimestre, repuntando levemente en los últimos tres meses. En síntesis, luego de la contracción huelguística de la etapa anterior, iniciada con la represión del Centenario, desde mayo de 1911 se inició una fase ascendente de un nuevo ciclo de conflictos gremiales. Como veremos más adelante, este período se extendió hasta el primer trimestre del año siguiente y tuvo su apogeo en las huelgas portuarias y ferroviarias de fines de 1911 y comienzos de 1912.

Huelgas en la Capital Federal

$1911-1912$

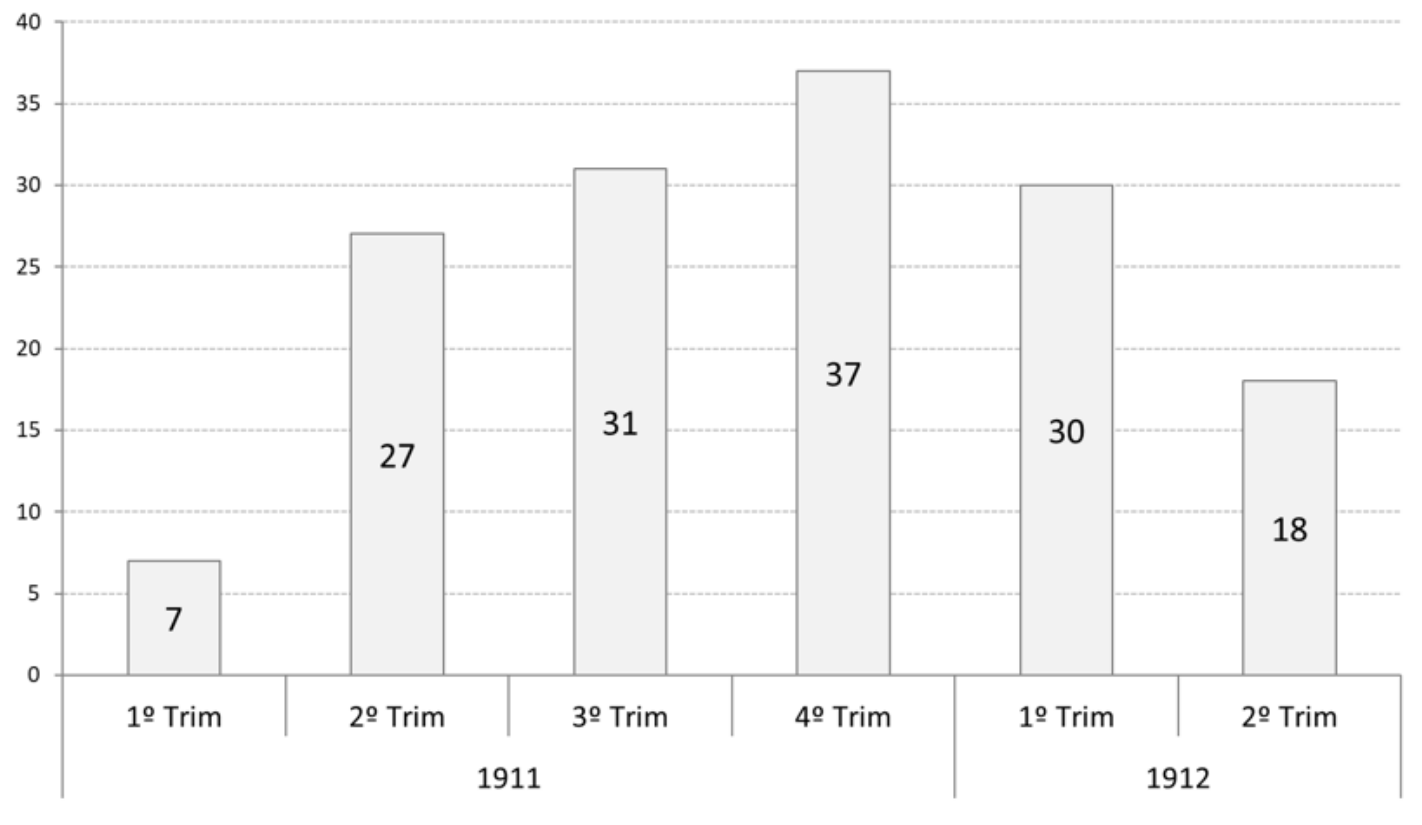

Fuente: Departamento Nacional del Trabajo

Los militantes sindicalistas fueron los primeros que registraron el incremento de las protestas gremiales. A comienzos de octubre de 1911, advirtieron que había indicios ciertos que anunciaban "la decisión del proletariado revolucionario de entrar en las batallas grandes". ${ }^{4}$ Un mes más tarde, aseguraban que "el inmenso estupor que ha inmovilizado las energías proletarias amenaza jal fin! trocarse en (...) un rugido de furor". ${ }^{5}$ A mediados de diciembre, con varios conflictos en marcha, aseguraron: "todo hace prever que volveremos a los grandes movimientos de otrora pero con más violencia". En el mismo artículo sostenían: "Nosotros vemos en los movimientos que se iniciaron los preámbulos para las grandes batallas del proletariado de este país" . ${ }^{6}$ En el momento de máxima agudización de la conflictividad obrera, los sindicalistas sostuvieron que la burguesía estaba sitiada por las fuerzas del proletariado. ${ }^{7}$ Los anarquistas también tomaron nota de la exacerbación de las luchas gremiales. A comienzos de 1912, mencionaban "el formidable movimiento de reivindicación proletaria que se desenvuelve en esta Capital y en el interior de la República”. 8

Dentro del ciclo ascendente de protestas obreras se destacaron seis huelgas, de las cuales tres estuvieron radicadas en el puerto (estibadores, carreros y marineros). La huelga más resonante la protagonizaron los maquinistas y foguistas de La Fraternidad. También paralizaron sus actividades los panaderos y ladrilleros. A continuación, narramos cada uno de estos conflictos. 


\section{LADRILLEROS}

Comenzamos en orden cronológico. La primera huelga importante la efectuaron los cortadores y peones de los hornos de ladrillos. Según el censo muncipal de 1909, en la Capital Federal trabajaban 3353 obreros en 94 fábricas y hornos de ladrillos. La enorme mayoría eran varones adultos (99,5\%) y extranjeros (83,7 \%). Más de las dos terceras partes de los propietarios también eran extranjeros (70 \%). ${ }^{9}$ Las condiciones de salubridad laboral eran de las peores de la industria. ${ }^{10} \mathrm{El}$ trabajo se realizaba a la intemperie y las jornadas laborales eran interminables. Entre los obreros de este gremio podemos distinguir tres sectores diferentes: cortadores, cargadores y peones. "El primero y el segundo, trabajan a destajo, (...) los peones comunes dependen de los cargadores, y trabajan a jornal". ${ }^{11}$ La producción de ladrillos tenía un fuerte componente estacional: "con la llegada del invierno los ladrillos crudos ya no se pueden secar y las heladas hacen que se cuarteen antes de meterlos en el horno" (Lucassen, Ferrandis Garrayo y Carazo, 2003). Entre septiembre y abril "se fabrica mucho ladrillo, pero en los [meses] restantes el trabajo es poco menos que nulo". ${ }^{12}$ Como veremos más adelante, la huelga se desencadenó en el momento de mayor demanda de mano de obra.

Ante las pésimas condiciones de trabajo, los obreros de cuatro o cinco hornos del barrio de Caballito se presentaron en el local de la CORA solicitando el apoyo de esa institución. La secretaría de la Confederación se puso a su disposición y redactaron un manifiesto haciendo "un llamado a los obreros de los Mataderos y Quinta Peña, los cuales acudieron entusiastas al local de la Confederación manifestando el deseo de formar la organización de los ladrilleros y extender el pliego de mejoras para todo el gremio". En vistas del éxito de esta primera convocatoria, "se lanzó otro manifiesto citando asamblea a los obreros de los hornos de la capital”. ${ }^{13}$ La reunión se realizó el sábado 16 de septiembre de 1911. Estuvieron presentes varios integrantes del Consejo Confederal de la CORA, quienes dirigieron palabras de aliento a los trabajadores. Se aprobó el pliego de reivindicaciones, donde se exigía una recomposición salarial y mejoras en las condiciones de trabajo. Los obreros declararon unánimemente la huelga del gremio. Además, la asamblea aprobó la constitución del Sindicato de Obreros Ladrilleros y Anexos. Se nombró una comisión provisoria, asignándole también las funciones de Comité de Huelga. Se organizaron diferentes grupos de propaganda que recorrían los hornos de la capital, acompañados por delegados de la CORA, "incitando a la huelga a los reacios". ${ }^{14}$ El momento elegido para iniciar la medida de fuerza era propicio para los trabajadores, "pues con la entrada de la primavera los hornos desarrollan mayor actividad". ${ }^{15}$ Los dirigentes sindicalistas estuvieron presentes desde el comienzo de la huelga y participaron de todas sus asambleas. ${ }^{16}$ El conflicto traspasó los límites de la Capital Federal, abarcando "casi todos los pueblos de los alrededores de la capital". ${ }^{17}$ Según el DNT, la medida de fuerza compendió a 4.500 trabajadores en la ciudad de Buenos Aires. Los sindicalistas estimaron en 30.000 los obreros en huelga. El conflicto adquirió inmensas proporciones. En el local de la CORA sesionó de manera permanente el Comité de Huelga. En el transcurso del conflicto, los trabajadores continuaron fortaleciendo su organización gremial. En la asamblea del domingo 8 de octubre se nombró la comisión administrativa del nuevo sindicato. ${ }^{18}$

La fuerte represión policial fue una característica que estuvo presente en todas las protestas gremiales de la época. La huelga de los ladrilleros no fue la excepción. La irrupción de la policía en los conflictos sindicales se convirtió en un recurso de uso frecuente. ${ }^{19}$ Los obreros en conflicto denunciaron que la policía se había "lanzado a «cazar» huelguistas". ${ }^{20}$ En diversas redadas policiales fueron detenidos decenas de obreros. ${ }^{21}$ Para evitar la propaganda de los huelguistas, el jefe de policía resolvió "que la guardia de seguridad de caballería y las comisarías seccionales ejerzan unan vigilancia especial en los hornos de ladrillos". ${ }^{22}$ A pesar de las persecuciones, los obreros se mantuvieron firmes. Entonces, los patrones acudieron al Departamento Nacional del Trabajo solicitando su mediación. El organismo oficial aceptó su petición e invitó a los 
huelguistas a parlamentar. Los trabajadores rechazaron el ofrecimiento. La resolución fue tomada primero por la Comisión Administrativa del gremio y luego refrendada en asamblea. ${ }^{23}$

La decisión de rechazar la mediación estatal revela la influencia que tuvieron los sindicalistas en la dirección del conflicto. Los socialistas reconocieron ese predominio. "El Departamento invitó a los huelguistas, pero como los dirigentes están inspirados por el consejo de la C.O.R.A., rechazaron el ofrecimiento”. El Partido Socialista lamentó esa resolución, aprobando la injerencia estatal. ${ }^{24}$ Los anarquistas, por el contrario, felicitaron a la conducción del sindicato. ${ }^{25}$ Los sindicalistas también aplaudieron la resolución adoptada por los obreros ladrilleros. ${ }^{26}$ La posición asumida por el sindicato tenía cierta dosis de osadía, porque en ese momento arreciaba la represión policial y crecía diariamente el número de prisioneros. Sin embargo, luego de dos meses de lucha, el conflicto se resolvió favorablemente para los trabajadores. La gran mayoría de los patrones del ramo aceptó el pliego de reivindicaciones exigido por los huelguistas. Los sindicalistas festejaron el triunfo de los obreros ladrilleros y reivindicaron especialmente sus métodos de lucha. Para ganar el conflicto, aseguraron, fue clave que los obreros hayan rechazado la mediación estatal, destacaron que no se dejaron "embaucar" por los ofrecimientos del DNT, que "se valió de todas las zalamerías que pudo". ${ }^{27}$ El apoyo brindado por la CORA seguramente fortaleció a los trabajadores en conflicto, pero se debe tener en cuenta, entre los motivos del triunfo obrero, el momento elegido para declarar la medida de protesta. La necesidad de la patronal de abastecer una demanda creciente de ladrillos en la primavera seguramente robusteció a las fuerzas del trabajo. La experiencia organizativa brindada por los militantes de la CORA y la estacionalidad en la producción de ladrillos coadyuvaron en favor de los huelguistas.

La huelga de los horneros inauguró un nuevo período de luchas obreras, caracterizado por conflictos gremiales de grandes dimensiones. Cada una de las principales huelgas que vinieron a continuación estibadores, carreros, marineros, etc.- reunió a miles de trabajadores. A su vez, la CORA se benefició con la incorporación de un sindicato de más de 4000 asociados cotizantes. De esta forma, el sindicalismo revolucionario extendía su influencia en el movimiento obrero. ${ }^{28}$ La victoria de los ladrilleros, aseguraban, confirmaba la justeza de su táctica.

\section{PanAderos}

Poco tiempo después de finalizada la huelga de ladrilleros, fueron los trabajadores de panaderías los que se lanzaron a la huelga. El sindicato que agrupa a los trabajadores del sector fue uno de las primeros en organizarse en el país, sus orígenes se remontan a la década de 1880 (Poy, 2014). La sociedad de resistencia de obreros panaderos tuvo una estrecha vinculación con el movimiento anarquista local, y llegó a constituirse en un punto de referencia ineludible para las asociaciones y grupos obreros de tendencia libertaria (Poy, 2014). El pan era uno de los alimentos más demandados, junto con la carne y la leche. ${ }^{29}$ En la Capital Federal trabajaban más de 6000 panaderos, en su gran mayoría varones y extranjeros. ${ }^{30}$ En 1911, en el mismo ámbito, había 463 panaderías, ${ }^{31}$ las dos terceras partes de los propietarios eran extranjeros. ${ }^{32}$ Entre los obreros panaderos había distintas categorías y oficios: maestros de pala, amasadores, ayudantes y repartidores. ${ }^{33}$ Los primeros eran los mejores pagos y cumplían un rol central en la organización del proceso de trabajo. ${ }^{34}$ Por lo tanto, el gremio de panaderos era importante por diversos motivos. En primer lugar, el pan ocupaba un lugar central en la dieta alimenticia de los porteños. En segundo lugar, reunía una importante cantidad de trabajadores, siendo uno de los rubros más numerosos de la ciudad. En tercer lugar, por la larga tradición de organización y lucha de los trabajadores panaderos y por la filiación ideológica libertaria, siendo una referencia para el anarquismo local.

La huelga de los panaderos se decidió en una asamblea realizada el domingo 10 de diciembre de 1911; en esa oportunidad "se reunió el gremio de obreros panaderos a fin de determinar su línea de conducta (...) se resolvió declarar la huelga general del gremio”. El pliego de condiciones reunía una serie de reivindicaciones 
referidas a las condiciones de trabajo. ${ }^{35}$ Inmediatamente, una vez conocida la noticia, la policía lanzó una feroz represión contra los trabajadores en conflicto. El sindicato organizó un Comité de Huelga, el cual emitió un comunicado donde se denunciaba esta situación: "La persecución de que se está haciendo víctima a los obreros panaderos por parte de la policía, es una monstruosidad". Sin embargo, la respuesta del Estado no fue exclusivamente represiva, sino que asumió una actitud bifronte, a los pocos días de iniciarse la medida de fuerza, el "Departamento Nacional de Trabajo, propuso su mediación para solucionar el conflicto". ${ }^{36} \mathrm{El}$ Estado, que se ofrecía para mediar en el conflicto, al mismo tiempo reprimía violentamente a los huelguistas. Decenas de obreros panaderos fueron apresados por la policía. A pesar de su larga tradición anarquista y antiestatal, los obreros panaderos, reunidos en asamblea, aceptaron la negociación ofrecida por el DNT. Para tal efecto, "se nombró una comisión encargada de entrevistarse con el presidente de esa institución" ${ }^{37}$ Una delegación obrera concurrió al DNT y se entrevistó con su director, Julio Lezana. Sin embargo, la mediación no prosperó, porque los representantes patronales rechazaron las gestiones auspiciadas por el DNT. Se citó a una nueva reunión. Una vez más, la comisión obrera asistió presta a negociar. Pero los patrones "se negaron a conversar con los obreros, afirmando que contaban con personal suficiente en las panaderías". En consecuencia, el rechazo patronal hizo naufragar las gestiones auspiciadas por el DNT. Los trabajadores, reunidos en asamblea, repudiaron al DNT, "tuvieron duras palabras de condenación para el departamento que les hizo acudir allí sin consultar antes la opinión de los patrones". ${ }^{38}$ La medida de fuerza abarcó a cerca de 2.500 trabajadores, es decir que la mayoría del gremio se mantuvo indiferente y no participó del conflicto. ${ }^{39}$ Por ese motivo, en la asamblea efectuada el día 24 de diciembre, los panaderos resolvieron "volver al trabajo en las condiciones anteriores" ${ }^{40}$ La medida de fuerza finalizó con la derrota de los huelguistas. Los obreros en conflicto no consiguieron quebrar la intransigencia patronal. ${ }^{41}$ En este caso, el trabajo de pinzas realizado por el Estado, recurriendo simultáneamente a la represión y al diálogo, resultó exitoso para las fuerzas patronales. La intransigencia de los dueños de panaderías y el desmedido espíritu de negociación del gremio contribuyeron al resultado desfavorable que sufrieron los trabajadores.

\section{ESTIBADORES Y CARREROS}

En forma paralela a la huelga de los panaderos, los obreros del puerto decidieron paralizar sus actividades. En el puerto de Buenos Aires trabajaban cerca de once mil estibadores: el $40 \%$ eran italianos, $25 \%$ españoles, $20 \%$ argentinos y $15 \%$ pertenecían a diversas nacionalidades. La mayoría tenían más de 30 años de edad. ${ }^{42}$ Los trabajadores no eran conchabados directamente por las empresas de navegación sino por contratistas. En diferentes ocasiones los obreros del puerto exigieron la eliminación de estos intermediarios, pero se toparon con la firme resistencia patronal. La Sociedad de Resistencia de Obreros del Puerto de la Capital (SROPC) se fundó en septiembre de $1901,{ }^{43}$ y hacia 1908 contaba con alrededor de 3000 cotizantes. ${ }^{44}$ La SROPC adhirió a la FORA anarquista, expresando así la influencia libertaria entre sus cuadros dirigentes (Abad de Santillán, 1933). Este sindicato ocupaba una posición estratégica dentro de la estructura económica del modelo agroexportador (Womack, 2007), esta particularidad le otorgaba un poder de fuego excepcional, pero también motivaba que sus acciones de protestas sean duramente castigadas.

El martes 12 de diciembre se realizó en el local de los carreros la asamblea de los obreros nucleados en la SROPC. ${ }^{45} \mathrm{El}$ secretario informó "a la numerosa asamblea (...) que los patrones no habían contestado al pliego de condiciones enviado por el gremio". Hicieron uso de la palabra varios obreros y denunciaron los bajos salarios y las pésimas condiciones de trabajo. Finalmente, "entre grandes aclamaciones de entusiasmo, la asamblea proclamó por unanimidad la huelga general para los obreros del puerto, Barracas y Mercado Central de Frutos". ${ }^{46}$ Como en el caso de los panaderos, en esta huelga también intervino el Departamento Nacional del Trabajo, un representante del ente oficial se acercó al local del sindicato y ofreció los servicios de esa 
institución para solucionar el conflicto. "El ofrecimiento del funcionario del Departamento del Trabajo fue llevado a la asamblea, promoviéndose sobre este asunto una animada discusión”. ${ }^{47}$ Luego de un prolongado y áspero debate, los trabajadores decidieron aceptar la mediación estatal.

Mientras el DNT invitaba a los obreros al diálogo, la policía reprimía a los huelguistas. El viernes 15, "fueron detenidos los conocidos estibadores Bernardo Ochoa, Serafín Romero y otros dos más cuyos nombres no hemos podido averiguar". De esa manera, se trataba "de inutilizar a los obreros más activos y (...) sembrar el desaliento en las filas huelguistas". ${ }^{48}$ El sábado 16 una delegación obrera se entrevistó con el Dr. Julio Lezana, presidente del DNT. El funcionario escuchó los reclamos obreros y citó a la comisión para el día siguiente, para conferenciar con los representantes patronales. ${ }^{49}$ El lunes 18 concurrieron nuevamente los delegados obreros al DNT; sin embargo, las gestiones resultaron infructuosas. ${ }^{50} \mathrm{El}$ doctor Lezana informó que "los patrones de la Bolsa y Cámara Mercantil habían rehusado la invitación para conferenciar con la comisión obrera". Los empresarios alegaron que "que contaban con personal suficiente y que para ellos la huelga no existía". ${ }^{11}$ El diario La Nación, comentando la negativa a negociar de la patronal portuaria, afirmaba: "La respuesta es (...) la misma que dieron los propietarios de panaderías" ${ }^{52}$

El domingo 17 de diciembre, reunidos en asamblea, los carreros del puerto acordaron solidarizarse con los estibadores en huelga. ${ }^{53}$ Publicaron un manifiesto donde pregonaban "que en lo sucesivo todo conductor se niegue a efectuar carga y descarga en el puerto de la Capital, Ribera, Barracas y Mercado Central de Frutos y con todo lo que esté relacionado con el conflicto de los obreros estibadores". ${ }^{54}$

El número de prisioneros se incrementaba diariamente. La policía actuaba como brazo armado de los empresarios, bastaba "una simple denuncia del gerente de la sociedad patronal para que la policía proceda a la detención" de los trabajadores marcados. ${ }^{55} \mathrm{Al}$ mismo tiempo, el ministro del interior, Indalecio Gómez, invitó a los trabajadores a negociar. Sin embargo, cuando la delegación obrera se hizo presente, el ministro les comunicó que no podía atenderlos por encontrarse muy ocupado. A pesar del desplante oficial, los huelguistas mantuvieron su predisposición al diálogo. Antes de retirarse, dejaron una nota "expresando al doctor Gómez que si deseaba entrevistarse con ellos volviera a llamarlos". ${ }^{56}$ Como veremos a continuación, la conflictividad en el puerto de Buenos Aires lejos de solucionarse se agravaría cuando los trabajadores marítimos decidan iniciar una huelga general en su sector.

\section{Marítimos}

Los trabajadores de a bordo estaban agrupados en la Federación Obrera Marítima (FOM). Este sindicato se fundó en abril de 1910, lo constituyeron marineros, mozos, trabajadores de sala de máquinas, cubierta y cocina. "Al agrupar de forma perdurable a las diversas categorías de trabajadores embarcados, la FOM se convirtió en el primer gremio por actividad de carácter nacional” (Caruso, 2012, p. 240). En el puerto de Buenos Aires trabajaban cerca de 4000 obreros marítimos en 1909 y 5600 en 1914 (Caruso, 2012, p. 95). Este gremio, al igual que los estibadores, ocupaba una posición estratégica dentro de la estructura socioeconómica del país.

En los últimos días del año 1911, el conflicto en el puerto se agravó. Los marineros y foguistas, nucleados en la FOM, realizaron el sábado 23 por la noche una asamblea general extraordinaria. "Después de una calurosa discusión (...) se acordó declarar la huelga general del gremio" ${ }^{57}$ Entonces, la paralización del puerto abarcaba cada vez más trabajadores, además de los estibadores y carreros, se sumaron los marineros y foguistas (Adelman, 1993; Caruso, 2016). Lejos de solucionarse, el conflicto continuó agravándose. El 30 de diciembre se reunieron los trabajadores agrupados en la Sociedad de Conductores de Carros. "En la asamblea se hallaban presentes un delegado de los obreros del puerto y otro de la Federación Obrera Marítima, quienes informaron a la asamblea del estado actual de las huelgas" ${ }^{58}$ Luego de las deliberaciones, resolvieron declarar la huelga 
general del gremio, a pedido de los trabajadores del puerto. ${ }^{59}$ Los carreros profundizaron su medida de fuerza "como acto de solidaridad con los obreros portuarios y marítimos" ${ }^{60}$ Apenas conocida la noticia, la policía redobló su asedio a los huelguistas, "se apresuró a clausurar el local de los carreros, con el propósito de no dejar reunir a los huelguistas" ${ }^{1}$ "En los primeros días del año 1912, el conflicto portuario se profundizó aún más. El domingo 7 de enero, los obreros caldereros se reunieron en un local del barrio de la Boca. La mayoría de los asambleístas se inclinó en favor de la huelga. ${ }^{62}$ De esta forma, más de 400 trabajadores caldereros, de 17 talleres y astilleros del puerto, se sumaron a la lucha.

\section{MAQUINISTAS Y FOGUISTAS}

La conflictividad gremial alcanzó su punto culminante cuando los maquinistas y foguistas se declararon en huelga. Los trabajadores de este sector estaban agrupados en La Fraternidad, uno de los sindicatos más antiguos del país, fundado en 1887. "Sus miembros se consideraban a sí mismos una elite dentro de la clase trabajadora; y en muchos aspectos lo eran" (Horowitz y Wolfson, 1985, p. 421). En ciertos casos ni siquiera se pensaban como parte del proletariado: "un maquinista no es un obrero" (Chiti y Agnelli, 1937, p. 265). La estrategia del sindicato se caracterizaba por su moderación, "procuró siempre evitar paros teniendo en cuenta los sagrados intereses públicos" (Chiti y Agnelli, 1937, p. 115). Hacia 1910 contaba con 86 seccionales y delegaciones y más de 6000 afiliados. Para esos años, en 1913, la Argentina contaba con más de 3500 locomotoras (Chiti y Agnelli, 1937). El poder de fuego del gremio residía, aquí también, en la posición estratégica que ocupaba. Este sindicato, distinguido por sus procedimientos mesurados, protagonizó en estos años una de las huelgas más importantes de su historia.

Luego de extensas negociaciones con las empresas, La Fraternidad decidió rechazar el arbitraje ofrecido por el gobierno e iniciar un paro general de actividades. ${ }^{63}$ La medida de fuerza se hizo efectiva a partir del domingo 7 de enero.

En ese contexto, de creciente agitación obrera, la conflictividad laboral arrastró a segmentos inesperados de la clase trabajadora. Sorpresivamente, los empleados de la Sociedad Protectora del Trabajo Libre (SPTL) se declararon en huelga. El diario La Nación manifestaba su asombro por la situación, porque "esta sociedad es de las denominadas rompehuelgas", sin embargo "su personal ha hecho abandono del trabajo en (...) adhesión a los demás obreros del puerto que se hallan en huelga, de manera que el caso resulta aún más sugerente" ${ }^{64}$ En ese momento, según las estimaciones policiales, el número total de huelguistas ascendía a 20.750 trabajadores. ${ }^{65}$ El órgano oficial de la CORA calculó en 35.000 el total de obreros en lucha. ${ }^{66}$

\begin{tabular}{|l|lrr|r|}
\hline \multicolumn{5}{|c}{$\begin{array}{c}\text { Obreros en huelga } \\
\text { (estimaciones policiales) } \\
\text { Enero de 1912 }\end{array}$} \\
\hline \multicolumn{1}{|c}{ Sector } & \multicolumn{1}{c|}{ Sindicato } & Huelguistas & $\%$ \\
\hline Maquinistas y Foguistas & La Fraternidad (LF) & 8.000 & $38,6 \%$ \\
\hline Estibadores & Sociedad de Resistencia de Obreros del Puerto (SROP) & 5.300 & $25,5 \%$ \\
\hline Marineros & Federación Obrera Marítima (FOM) & 3.100 & $14,9 \%$ \\
\hline Carreros & Sociedad de Conductores de Carros (SCC) & 2.400 & $11,6 \%$ \\
\hline Peones del puerto & Sociedad Protectora del Trabajo Libre (SPTL) & 1.100 & $5,3 \%$ \\
\hline Caldereros & Sociedad de Obreros Caldereros y Anexos (SOCYA) & 600 & $2,9 \%$ \\
\hline Varios & & 250 & $1,2 \%$ \\
\hline Total & & 20.750 & $\mathbf{1 0 0 , 0 \%}$ \\
\hline
\end{tabular}




\section{LAS DERROTAS}

Hacia mediados de enero se alcanzó el pico más elevado de la conflictividad gremial. La huelga ferroviaria comenzó a paralizar la economía, afectando la circulación y los precios de las mercancías. "Ya hace días que se hacen sentir en la población de toda la República las consecuencias de la huelga ferroviaria. La falta de artículos de primera necesidad es sensible y los víveres en general se han encarecido". ${ }^{67}$ Sin embargo, a partir de ese momento, cada una de estas huelgas, una tras otra, caerán derrotadas. Por lo tanto, este ciclo de protestas sindicales concluyó en un fracaso estrepitoso de los gremios en lucha y tuvo consecuencias desastrosas para el conjunto del movimiento obrero. Los carreros fueron el primer gremio en retornar a sus labores. ${ }^{68}$ La medida de fuerza de estos trabajadores se fue deshilachando con el correr de los días. ${ }^{69}$ Recordemos que este sindicato se había declarado en huelga en solidaridad con los obreros del puerto. El día 25 de enero, la Sociedad de Conductores de Carros resolvió volver al trabajo. ${ }^{70}$ Con esta decisión, los carreros abandonaron a su suerte a los trabajadores portuarios, que mantenían su medida de fuerza. Esta resolución debilitaba a los obreros en conflicto y preanunció lo que vendría.

Al día siguiente, el viernes 26 de enero, se reunieron los trabajadores nucleados en la Sociedad de Resistencia de Obreros del Puerto. Luego de un extenso debate, decidieron reanudar sus labores a partir del día lunes $29 .^{71}$ Los obreros del puerto levantaron la huelga sin que sus demandas hayan sido atendidas. Los anarquistas reconocieron la derrota. "Después de una lucha que duró más de mes y medio han resuelto volver al trabajo en las condiciones anteriores esperando otra oportunidad para volver a la lucha en demanda de las mejoras pedidas" ${ }^{72}$ Los sindicalistas también advirtieron el resultado desfavorable de la medida de fuerza. "La huelga de conductores de carros, cargadores y descargadores del puerto, peones de barracas y Merado de Frutos, ha terminado con un fracaso (...) volviendo los obreros a sus antiguos puestos, incondicionalmente". ${ }^{73}$ Antes de levantar la huelga, los obreros del puerto visitaron en repetidas oportunidades al titular del DNT y al ministro del Interior. Consintieron sin inconvenientes las propuestas gubernamentales de mediación estatal. Estuvieron permanentemente abiertos al diálogo con las autoridades nacionales y los representantes patronales. Los delegados obreros concurrieron el 12 y el 18 de enero al DNT para entrevistarse con su titular. ${ }^{74}$ Los días 13, 15 y 25 asistieron al Ministerio del Interior y se reunieron con Indalecio Gómez. ${ }^{75}$ En definitiva, los trabajadores portuarios demostraron en repetidas oportunidades su voluntad inalterable de arribar a un acuerdo negociado. Tampoco tuvieron inconvenientes en aceptar y recurrir a la mediación estatal, tanto del DNT como del ministro del Interior. Sin embargo, los patrones se negaron sistemáticamente a negociar con los obreros en huelga.

Los marineros y foguistas tampoco consiguieron quebrar la resistencia de los empresarios del sector. En una asamblea realizada el día 25 de enero resolvieron "renunciar al aumento de salario y volver al trabajo si los patrones «por razones de humanidad» entraran a considerar las otras cláusulas del pliego de condiciones". Después de conocer esa decisión, La Vanguardia afirmó: "Se puede decir que la huelga declarada por la Federación Obrera Marítima toca a su término”. La FOM envió una nota de agradecimiento al abogado del DNT, Julio Villafañe, quien ofició de representante ante los armadores y los Ministerios de Marina y del Interior (Caruso, 2013). El diario socialista, siempre cauto, medido y propenso a las soluciones negociadas, consideró que la nota de la FOM era "demasiado conciliatoria". ${ }^{76}$ Finalmente, luego de 43 días de conflicto, la Federación Obrera Marítima resolvió levantar la huelga. "Los marineros y foguistas han vuelto a bordo sin alcanzar la más leve mejora”. La derrota de los marítimos se había consumado. Su secretario general, entrevistado por La Vanguardia, declaraba: "dedicaremos todos nuestros esfuerzos a fortalecer la organización del gremio, levantando un buen registro de socios, creando al mismo tiempo una estadística con todos los datos relacionados con la gente de mar y organizando seriamente el servicio de cobradores" ${ }^{77}$ Los anarquistas también criticaron la conducta de la FOM en el conflicto. "La actitud de los obreros del Puerto ha tenido bastante que lamentar, especialmente por consentir la intervención de elementos políticos 
y las continuas entrevistas con los agentes del gobierno". ${ }^{78}$ Por último, luego de 48 días de paro, el 25 de febrero de 1912, arribaron a un acuerdo el gobierno las empresas y La Fraternidad. Los términos del arreglo fueron profundamente desventajosos para los trabajadores. Los ferroviarios decidieron levantar la huelga obteniendo a cambio solo promesas, la patronal se comprometió a reincorporar progresivamente a los trabajadores despedidos. De esta manera, los maquinistas y foguistas abandonaron la consigna de "todos o ninguno" por "readmisión gradual" ${ }^{79}$ Además, el pliego de reivindicaciones quedaba supeditado a la consideración del gobierno. "Las mejoras solicitadas dependerán de una reglamentación del trabajo decretada por el gobierno" ${ }^{80}$ El ciclo de protestas obreras llegaba a su fin, ${ }^{81}$ el saldo para los trabajadores era ampliamente desfavorable. Las decenas de miles de trabajadores portuarios y ferroviarios, que se lanzaron a la lucha, no consiguieron doblegar la intransigencia patronal, sus organizaciones gremiales terminaron muy debilitadas, quedaron un tendal de cesanteado y muchos obreros sufrieron los rigores de la represión estatal.

\section{Conclusiones}

Este importante ciclo de protestas obreras nos permite extraer varias conclusiones. En primer lugar, se observa con claridad la respuesta del Estado ante la conflictividad gremial. En todos los casos se desplegó una política bifronte, una estrategia que comprendía dos mecanismos que se ponían en práctica de manera simultánea. La respuesta inmediata estaba en manos de la policía, que se encargaba de perseguir y encarcelar a los huelguistas, apuntando especialmente a los activistas y organizadores obreros. ${ }^{82}$ Para realizar esta faena contaba con el respaldo de la Ley de Defensa Social, que le otorgaba plenos poderes para actuar de manera completamente discrecional. En forma paralela, el DNT ofrecía sus servicios para mediar entre obreros y patrones, con el objetivo declarado de arribar a un acuerdo negociado. En algunas ocasiones, como en el caso de los estibadores, también intervino como mediador el Ministerio del interior. Entonces, mientras los trabajadores en huelga eran perseguidos, encarcelados y sus locales eran clausurados (como en el caso de los carreros) por la policía, al mismo tiempo, el DNT -y en ciertas ocasiones la cartera política- se ofrecía como árbitro para arribar a un acuerdo negociado. El Estado recurrió a este dispositivo de tenazas sobre el movimiento obrero en los casos aquí analizados. Este mecanismo dual se utilizó de manera sistemática y tuvo una influencia decisiva en los reveses sufridos por las fuerzas del trabajo. Los sectores en conflicto no supieron resolver con éxito las estratagemas que desplegaron la patronal y el Estado para enfrentar estas medidas de fuerza.

En segundo lugar, debemos destacar la respuesta de las organizaciones obreras ante las ofertas de mediación estatal. Recordemos que, unos años antes, las dos centrales obreras de la época habían rechazado de forma categórica todo tipo de vínculo con el Estado o su intervención en los conflictos gremiales. En su cuarto congreso, efectuado siete años antes, la FORA declaraba "que toda intromisión de los poderes públicos en los conflictos entre el Capital y el Trabajo constituye un atentado a la libertad social e individual" ${ }^{83}$ En 1907 el DNT invitó a la Unión General de Trabajadores (UGT) a conformar tribunales de arbitraje. La central obrera denegó su participación, respondiendo que "toda comisión de arbitraje propuesta por instituciones de la clase burguesa (como es ese «Departamento del Trabajo») no puede tener por resultado otra cosa que no sea la defensa de los intereses capitalistas". En la misma nota se afirmaba: "rechazamos toda armonía entre capital y trabajo". ${ }^{84}$ A pesar de estas declaraciones, realizadas solo unos pocos años antes, la gran mayoría de los gremios consintió y/o solicitó la intervención del Estado en los conflictos obreros. Los panaderos y estibadores, dos gremios de larga tradición anarquista, se reunieron con el presidente del DNT y el ministro del interior. Los marítimos, dirigidos por el entonces anarquista Francisco García, agradecieron públicamente a Julio Villafañe, abogado del DNT, por sus gestiones en favor de la FOM. La Fraternidad sostuvo negociaciones durante meses antes de declarar la huelga general del gremio. Mientras las organizaciones obreras aceptaban y reclamaban la intervención del Estado en los diferentes conflictos, las patronales se mostraron intransigentes, rechazando su participación en las instancias de arbitraje que 
promovía el DNT. La actitud de la mayoría de los gremios, en los conflictos aquí reseñados, nos permite apreciar un giro acentuado que se ha producido en las estrategias de lucha de la clase trabajadora. En estos años, se profundiza la tendencia a la aceptación del Estado como árbitro en las disputas gremiales. Anteriormente, existieron casos de mediación estatal, ${ }^{85}$ después del Centenario esta directriz se consolidó y los gremios se mostraron cada vez más propensos a la concertación con los poderes públicos. La confianza que desarrollaron los gremios en los dispositivos de negociación estatal debilitaron las capacidades de respuesta de la clase trabajadora. Generando debates internos que fragmentaron a las fuerzas obreras.

En tercer lugar, en todos los casos, excepto en el conflicto de los ladrilleros, la patronal adoptó una posición absolutamente contraria al diálogo y la mediación estatal. Esta firme disposición de las fuerzas del capital estaría indicando su convencimiento en las debilidades de las organizaciones obreras, golpeadas por la represión del Centenario y desorientadas por la estrategia de pinzas que desplegaba el Estado. En cualquier caso, la decisión de las patronales apuntaba a defender las posiciones conquistadas, no ceder ante las demandas obreras, impidiendo la recuperación de las fuerzas del trabajo. Esta resuelta determinación de la patronal y las debilidades del movimiento gremial coadyuvaron a las derrotas sufridas por las fuerzas del trabajo.

En cuarto lugar, pero íntimamente relacionado con los puntos anteriores, después del Centenario desaparece del horizonte de posibilidades la huelga general como método de lucha. En la primera década del siglo XX las centrales obreras habían declarado en varias oportunidades huelgas generales en solidaridad con algún sector en lucha ${ }^{86}$ o en respuesta a algún acontecimiento internacional. ${ }^{87}$ La dureza de la represión desatada en el Centenario, el debilitamiento de las organizaciones gremiales y la aplicación de la Ley de Defensa Social, atenuaron las perspectivas de una amplia confrontación con el Estado. La estrategia oficial de arbitraje en los conflictos obreros también erosionó la radicalización de las huelgas parciales. A mediados de diciembre, con las huelgas de panaderos y de los obreros del puerto en marcha, la FORA emitió un tímido comunicado donde realizaba apreciaciones demasiado generales, incitaba a los trabajadores "a proseguir enérgicos en la obra de reorganización y de resistencia". ${ }^{88}$ En enero de 1912, en el clímax de la confrontación social, la FORA apenas insinúa que "si es que llega el caso", podría llegar a considerar la realización de una huelga general, que finalmente nunca se realizó. Más aun, tiene que salir a responder por su pasividad, diciendo que "la Federación jamás negó la solidaridad y en esta emergencia menos" ${ }^{89}$ La Confederación Obrera Regional Argentina (CORA), de orientación sindicalista, tampoco realizó ninguna convocatoria a la huelga general. Las vacilaciones de las centrales obreras expresan el estado de ánimo y las debilidades por las que atravesaban las asociaciones gremiales.

En quinto lugar, dentro del movimiento obrero, los gremios de tradición anarquista no tuvieron inconvenientes en concertar con el Estado, aceptando el arbitraje propuesto por el DNT. Este hecho estaría expresando un cambio de orientación dentro del gremialismo anarquista, pero su análisis excede los límites del presente trabajo. La Fraternidad, bajo la influencia del Partido Socialista (PS), negoció durante meses y recién recurrió al paro cuando el prolongado arbitraje no arrojó ningún resultado positivo. El único gremio que rechazó la intervención estatal fue el de los ladrilleros, orientado por el sindicalismo revolucionario. En este caso, resulta necesario considerar el componente estacional, que favoreció y fortaleció a los trabajadores en conflicto.

En definitiva, el movimiento obrero argentino logró recuperarse rápidamente del duro revés sufrido alrededor del Centenario. Desde mayo de 1911 hasta febrero de 1912 tuvo lugar un ciclo de protestas obreras de gran envergadura. Excepto el caso de los ladrilleros, el resto de los conflictos terminó en duras derrotas para la clase trabajadora. El análisis de estos conflictos nos revela un movimiento gremial menos radicalizado que el de la primera década del siglo XX, donde la perspectiva de la huelga general no se encontraba presente. El Estado y los líderes gremiales estaban mucho más predispuestos a la negociación que en años anteriores, en un contexto atravesado por una fuerte represión, apoyada en un aparato legal que le daba sustento. Cabe analizar en el futuro en qué medida este ciclo de protestas y su deriva de derrotas obreras preanunciaron los cambios que tuvieron lugar en el sindicalismo argentino en los años posteriores. 


\section{FUENTES}

Anuario Estadístico de la Ciudad de Buenos Aires (1912)

Boletín del Departamento Nacional del Trabajo

Censo general de población, edificación, comercio e industrias de la Ciudad de Buenos Aires (1909).

El Obrero Panadero

La Acción Obrera

La Confederación

La Nación

La Organización

La Organización Obrera

La Protesta

La Vanguardia

Libro de Actas de la UGT

Tercer Censo Nacional (1914).

\section{REFERENCIAS}

Abad de Santillán, D. (1933). La FORA: ideología y trayectoria del movimiento obrero revolucionario en la Argentina. Nervio.

Adelman, J. (1993). State and Labour in Argentina: The Portworkers of Buenos Aires, 1910-21. Journal of Latin American Studies, 25, 73-102.

Ansaldi, W. (2012). «Que voten antes que nos boten»: La reforma electoral de 1912. Estudios Sociales, 43, 59-90.

Barrancos, D. (1991). Educación, cultura y trabajadores (1890-1930). Centro Editor de América Latina.

Barry, V. (2009). Policía y Centenario. Rasgos de la policía de la ciudad de Buenos Aires en los festejos de 1910. En E. Bohoslavsky, L. Caimari, y C. Schettini, La policia en perspectiva bistórica. Argentina y Brasil (del siglo XIX a la actualidad) (CD-Rom).

Belkin, A. (2015). La huelga general de enero de 1907 y las estrategias políticas de socialistas, anarquistas y sindicalistas revolucionarios. Estudios del Trabajo, 49, 31-58.

Belkin, A. (2019). La huelga general por el asesinato de Ferrer: Fragmentación gremial y disputas políticas (octubre de 1909). Almanaque histórico latinoamericano, 23, 7-19.

Belkin, A. (2020). El rol protagónico de la Confederación Obrera Regional Argentina en la huelga general del Centenario, mayo de 1910. Revista Divergencia, 14, 115-132.

Bilsky, E. J. (1985). La FORA y el movimiento obrero (1900-1910), vols. 1 y 2. CEAL.

Bilsky, E. J. (1986). Esbozo de historia del movimiento obrero argentino: Desde sus orígenes hasta el advenimiento del peronismo. Fundación Simón Rodríguez - Biblos.

Boido, J. O. (2002). La primera huelga general en la República Argentina (1902). Sus características y significados, como expresión de la presencia de los obreros como clase en la luch a político-económica. Universidad Nacional de Luján.

Botana, N. R. (1985). El orden conservador: La politica argentina entre 1880 y 1916. Hyspamérica.

Camarero, H. (2015). El Partido Socialista de la Argentina y sus espinosas relaciones con el movimiento obrero: Un análisis del surgimiento y disolución del Comité de Propaganda Gremial, 1914-1917. Revista Izquierdas, 22, 158-179.

Caruso, L. G. (2012). Los trabajadores maritimos del Puerto de Buenos Aires: Condiciones laborales, organización sindical y cultura politica, 1890-1920. Tesis de Doctorado. 
Caruso, L. G. (2013). Las huelgas marítimas y el Departamento Nacional del Trabajo: Conflicto obrero e intervención estatal (1890-1920). En Pensar el Estado. Las instituciones laborales en Argentina durante la primera mitad del siglo $X X$. Edhasa.

Caruso, L. G. (2016). Embarcados. Los trabajadores maritimos y la vida a bordo: Sindicato, empresas y Estado en el puerto de Buenos Aires, 1889-1921. Imago Mundi.

Casaretto, M. S. (1946). Historia del movimiento obrero argentino: Resumen: Vol. I. [s.n.].

Castro, M. O. (2012). El ocaso de la república oligárquica: Poder, política y reforma electoral, 1898-1912. Edhasa.

Ceruso, D. (2015). La izquierda en la fábrica la militancia obrera industrial en el lugar de trabajo, 1916-1943. Imago Mundi.

Chiti, J. B., y Agnelli, F. (1937). $50^{\circ}$ aniversario de La Fraternidad. Fundación desarrollo obra. Imprenta de La Fraternidad.

Costanzo, G. A. (2007). Lo inadmisible hecho historia. La Ley de Residencia de 1902 y la Ley de Defensa Social de 1910. Sociedad, 26, 1-13.

Garguin, E. (1999). La marea roja. El triunfo socialista en las elecciones porteñas de 1913. Sociohistórica, 6, 147-181.

Garguin, E. (2000). Relaciones entre Estado y sindicatos durante los gobiernos radicales, 1916-1930. En Argentina: Trabajadores entre dos guerras (pp. 87-117). Eudeba.

Godio, J. (1972). El movimiento obrero y la cuestión nacional. Argentina: Inmigrantes asalariados y lucha de clases, 1880-1910. Erasmo.

Gordillo, M. (1988). La Fraternidad en el movimiento obrero: Un modelo especial de relación (1916-1922). CEAL.

Horowitz, J. (2015). El radicalismo y el movimiento popular (1916-1930). Edhasa.

Horowitz, J. y Wolfson, L. (1985). Los trabajadores ferroviarios en la Argentina (1920-1943). La formación de una elite obrera. Desarrollo Económico, 99, 421-446.

Iñigo Carrera, N. (2000). La estrategia de la clase obrera: 1936. PIMSA-La rosa blindada.

Iñigo Carrera, N. (2013). Aproximación al análisis del centenario como hito en la historia de la confrontación social argentina. Pimsa Documentos y comunicaciones, 14, 69-116.

Iscaro, R. (1958). Origen y desarrollo del movimiento sindical argentino. Anteo.

Justo López, M. (2005). De la república oligárquica a la república democrática. Estudio sobre la reforma política de Roque Sáenz Peña. Lumiere.

Korzeniewicz, R. P. (1989). Labor Unrest in Argentina, 1887-1907. Latin American Research Review, 24(3), $71-98$.

Korzeniewicz, R. P. (1995). Labor Unrest in the World-Economy, 1870-1990. Review (Fernand Braudel Center), 18(1), 105-116.

Lucassen, J., Ferrandis Garrayo, M. L., y Carazo, J. A. (2003). La fabricación de ladrillos en Europa occidental y la India: Un intento de historia comparada del trabajo. Historia Social, 45, 3-33.

Marotta, S. (1961). El movimiento sindical argentino: Su génesis y desarrollo. Periodo 1907-1920: Vol. II. Lacio.

Monserrat, M. A. (2011). Los trabajadores ferroviarios: Sus luchas y organizaciones sindicales en el contexto de la Argentina gobernada por el radicalismo (1916 - 1930). Cuadernos del Ciesal, 97-118.

Oddone, J. (1975). Gremialismo proletario argentino. Líbera.

Palermo, S. (2009). Masculinidad, conflictos y solidaridades en el mundo del trabajo ferroviario en Argentina (1912-1917). Revista Mundos do Trabalho. Publicao Eletronica Semestral do GT Mundos do Trabalho, 1, 94-123.

Poy, L. (2014). Los origenes de la clase obrera argentina: Huelgas, sociedades de resistencia y militancia política en Buenos Aires, 1888-1896. Imago Mundi.

Rock, D. (1977). El radicalismo argentino, 1890-1930. Amorrortu.

Rotondaro, R. (1971). Realidad y cambio en el sindicalismo. Pleamar.

Suriano, J. (1988). Trabajadores, anarquismo y Estado represor: De la ley de residencia a la ley de defensa social (1902-1910). Centro Editorial de América Latina. 
Suriano, J. (1991). Estado y conflicto social: El caso de la huelga de maquinistas ferroviarios de 1912. Boletín del Instituto de Historia Argentina y Americana "Dr. Emilio Ravignani", 91-115.

Suriano, J. (Ed.). (2000). La cuestión social en la Argentina 1870-1943. La Colmena.

Suriano, J. (2001). Anarquistas: Cultura y politica libertaria en Buenos Aires: 1890-1910. Manantial.

Suriano, J. (2010). Los festejos del Primer Centenario de la Revolución de Mayo y la exclusión del movimiento obrero. Revista de Trabajo, 8, 19-28.

Tortti, M. C. (1989). Estrategia del Partido Socialista. Reformismo politico y reformismo sindical. CEAL.

Womack, J. (2007). Posición estratégica y fuerza obrera: Hacia una nueva historia de los movimientos obreros. Fondo de Cultura Económica.

\section{Notas}

1 Estos años fueron analizados especialmente desde la perspectiva del sistema político, por la novedad que representó la Ley Sáenz Peña. Es decir, fueron más estudiados "desde arriba" que "desde abajo" (Ansaldi, 2012; Botana, 1985; Castro, 2012; Garguin, 1999; Justo López, 2005).

2 En diversas obras sobre el movimiento obrero se encuentran referencias contextuales o descripciones puntuales, pero ninguna aborda en profundidad este período (Bilsky, 1986; Casaretto, 1946; Rock, 1977; Rotondaro, 1971).

3 Los socialistas crearon un organismo especial para incidir en este proceso. El domingo 9 de octubre de 1910 se reunieron cerca de 40 militantes socialistas y formaron el Grupo de Propaganda Gremial. El objetivo del nuevo organismo era "trabajar en el seno de las organizaciones obreras con el objeto de orientarlas en la táctica socialista". Para integrar el grupo era condición ser afiliado al partido y al sindicato correspondiente (ver "Grupo de propaganda", La Vanguardia, XVI, 1395, 11/10/1910, p. 3). Sus integrantes afirmaban que "la reorganización de la clase trabajadora debe ser llevada a cabo cuanto antes por parte de los socialistas" (en "FORUM: los socialistas ante el actual estado de la organización gremial”, La Vanguardia, XVI, 1416, 4/11/1910, p. 2). Por ese motivo, alentaron a sus compañeros a participar de la iniciativa: "es preciso (...) que todos los que somos proletarios socialistas estemos en ese organismo" (en "FORUM: a obrar!", La Vanguardia, XVI, 1420, 9/11/1910, p. 3).

4 "Renacimiento combativo", La Acción Obrera, VII, 200,7/10/1911, p. 1.

5 "La hora se acerca", La Acción Obrera, VII, 206, 18/11/1911, p. 1.

6 "La vida obrera: renacimiento combativo", La Acción Obrera, VII, 210, 16/12/1911, p. 3.

7 "Sitio del proletariado a la ciudadela burguesa", La Acción Obrera, VII, 214, 13/1/1912, p. 1.

8 “iA lucha!", La Protesta, XV, 1920, 9/1/1912, p. 1.

9 Censo general de población, edificación, comercio e industrias de la Ciudad de Buenos Aires, octubre de 1909, pp. 146 y ss.

10 "Uno de los más penosos y antihigiénicos trabajos, por las condiciones en que deben practicarlo, es el de los que se dedican a la fabricación de ladrillos" (en "Cortadores de ladrillos", La Organización, I, 12, noviembre de 1901, p. 3).

11 Boletín del Departamento Nacional del Trabajo, no 21, 30/11/1912, p. 313.

12 Boletin del Departamento Nacional del Trabajo, no 4, 1/3/1908, p. 26.

13 "Huelga de los Obreros Ladrilleros: 15.000 obreros en lucha", La Acción Obrera, VII, 198, 23/9/1911, p. 4.

14 "Sociedades gremiales", La Vanguardia, XVIII, 1685, 17/9/1911, p. 1.

15 "La huelga de ladrilleros", La Vanguardia, XVII, 1687, 20/9/1911, p. 3.

16 "La huelga de los horneros: la asamblea de ayer", La Vanguardia, XVIII, 1696, 30/9/1911, p. 1.

17 "La gran huelga de ladrilleros", La Acción Obrera, VII, 199, 30/9/1911, p. 1.

18 "La huelga de ladrilleros", La Vanguardia, XVIII, 1704, 10/10/1911, p. 1.

19 "La huelga de los ladrilleros", La Protesta, XIV, 1908, 26/9/1911, p. 4.

20 "La policía en las huelgas", La Vanguardia, XVII, 1710, 17/10/1911, p. 1.

21 Un listado parcial de los trabajadores encarcelados se encuentra en "La huelga de los ladrilleros", La Acción Obrera, VII, 202, 21/10/1911, p. 4.

22 "La huelga de horneros", La Nación, XLII, 14494, 15/10/1911, p. 13. Ver también "La huelga de horneros", La Vanguardia, XVIII, 1712, 19/10/1911, p. 2.

23 "La huelga de ladrilleros", La Acción Obrera, VII, 203, 28/10/1911, p. 3.

24 "Sociedades gremiales: la huelga de ladrilleros", La Vanguardia, XVIII, 1713, 20/10/1911, p. 1.

25 "La huelga de ladrilleros", La Protesta, XIV, 1910, 1/11/1911, p. 4.

26 "La huelga de ladrilleros", La Acción Obrera, VII, 203, 28/10/1911, p. 3.

27 "El movimiento de los obreros Ladrilleros", La Acción Obrera, VII, 206, 18/11/1911, p. 4. 
28 El militante sindicalista Antonio Marinelli fue nombrado por el gremio de ladrilleros para cobrar las cotizaciones mensuales de los socios (ver "Sociedades gremiales: ladrilleros y anexos", La Vanguardia, XVIII, 1741, 22/11/1911, p. 2).

29 Anuario Estadistico de la Ciudad de Buenos Aires, XXII, 1912, p. XXVIII.

30 Según el Censo General de Población, Edificación, Comercio e Industrias de la Ciudad de Buenos Aires de 1909 registra 6719 panaderos, siendo el $85 \%$ extranjeros y el 98 \% varones. El Tercer Censo Nacional, realizado en 1914, arroja una cifra similar, 6107 panaderos, donde el 89 \% eran extranjeros y sólo el 1 \% mujeres. En El Obrero Panadero, órgano de la Sociedad Cosmopolita de Resistencia y Colocación de Obreros Panaderos, se estima que en 1894 residían en la Ciudad de Buenos Aires cerca de 5000 panaderos (ver "Los obreros panaderos y los otros gremios", El Obrero Panadero, 1, 3, 16/10/1894, p. 2).

31 Anuario Estadistico de la Ciudad de Buenos Aires, XXII, 1912, p. 71.

32 Censo general de población, edificación, comercio e industrias de la Ciudad de Buenos Aires, octubre de 1909, Tomo I, p. 150.

33 Boletín del Departamento Nacional del Trabajo, no 3, 31/12/1907, p. 349.

34 "Una cosa solo lamentamos sensiblemente, y es que existen en Tucumán algunos maestros de pala que siguiendo el régimen antiguo, cometen abusos sobre los demás compañeros, por el solo hecho de que esos maestros se consideran superiores a los que en la cuadra ocupan plazas bajas" (ver "En buen camino", El Obrero Panadero, 11, 25, 9/6/1900, p. 1).

35 "Huelga general de obreros panaderos”, La Vanguardia, XVIII, 1758, 12/12/1911, p. 1.

36 "La huelga de panaderos", La Protesta, XIV, 1917, 19/12/1911, p. 4.

37 "Movimiento obrero: los gremios en huelga", La Vanguardia, XVIII, 1761, 15/12/1911, p. 1.

38 “Obreros Panaderos”, La Vanguardia, XVIII, 1763, 17/12/1911, p. 2.

39 "Obreros Panaderos", La Vanguardia, XVIII, 1769, 24/12/1911, p. 2.

40 “Movimiento obrero: los panaderos", La Protesta, XV, 1919, 2/1/1912, p. 4.

41 Los anarquistas habían denunciado la "inconciencia de algunos crumiros y la casi completa falta de solidaridad de los repartidores" (en "La huelga de panaderos", La Protesta, XIV, 1918, 26/12/1911, p. 3).

42 Boletin del Departamento Nacional del Trabajo, n 6, 30/09/1908, pp. 348 y ss.

43 “Movimiento obrero", La Protesta, V, 141, 28/9/1901, p. 3 y "Nuevas sociedades de resistencia”, La Organización Obrera, I, 2, septiembre de 1901, p. 4.

44 La Unión Obrera, III, 43, marzo de 1908, p. 3.

45 "La huelga de los obreros del puerto", La Protesta, XIV, 1917, 19/12/1911, p. 4.

46 "Movimiento obrero: los gremios en huelga", La Vanguardia, XVIII, 1759, 13/12/1911, p. 1.

47 “Movimiento obrero: obreros del puerto", La Vanguardia, XVIII, 1761, 15/12/1911, p. 1.

48 “Obreros del Puerto", La Vanguardia, XVIII, 1762, 16/12/1911, p. 1.

49 “Obreros del Puerto”, La Vanguardia, XVIII, 1763, 17/12/1911, p. 1.

50 “Trabajadores del puerto”, La Protesta, XIV, 1918, 26/12/1912, p. 3.

51 “Obreros del Puerto", La Vanguardia, XVIII, 1764, 19/12/1911, p. 1.

52 "Conflictos obreros", La Nación, XLII, 14560, 19/12/1911, p. 10.

53 "La solidaridad de los carreros", La Protesta XIV, 1918, 26/12/1912, p. 3.

54 "La solidaridad de los carreros", La Protesta XIV, 1918, 26/12/1912, p. 3.

55 “Obreros del Puerto”, La Vanguardia, XVIII, 1766, p. 1.

56 “Movimientos obreros: la huelga de estibadores”, La Nación, XLII, 1456, 23/12/1911, p. 9.

57 “Marineros y foguistas: declaración de la huelga”, La Vanguardia, XVIII, 1770, 26/12/1912, p. 1.

58 “Conductores de Carros”, La Vanguardia, XVIII, 1775, 31/12/1911, p. 1.

59 "Los carreros en huelga general”, La Protesta, XV, 1919, 2/1/1912, p. 4.

60 "Conflictos obreros: huelga general de carreros", La Nación, XLII, 14572, 31/12/1911, p. 9.

61 "Huelga general de carreros", La Acción Obrera, VII, 213, 6/1/1912, p. 3.

62 "Obreros caldereros", La Vanguardia, XVIII, 1781, 9/1/1912, p. 2.

63 "Conflictos obreros", La Nación, XLIII, 14574, 3/1/1912, p. 11.

64 “El paro en el puerto”, La Nación, XLIII, 14579, 9/1/1911, p. 12.

65 "Obreros del Puerto y Conductores de Carros", La Vanguardia, XVIII, 1781, 9/1/1912, p. 2.

66 “Las huelgas obreras del momento", La Confederación, II, 12, 15/1/1912, p. 1.

67 “Consecuencias de la huelga”, La Protesta, XV, 1922, 22/1/1912, p. 2.

68 "El paro en el puerto", La Nación, XLIII, 14596, 26/1/1912, p. 10.

69 "La huelga portuaria", La Vanguardia, XVIII, 1792, 21/1/1912, p. 2; "La huelga del puerto, barracas de lana, mercado de frutos y carreros: reflexiones sobre su fracaso”, La Acción Obrera, VII, 217, 3/2/1912, p. 1.

70 "Puesto el asunto a votación, 192 [64\%] conductores votaron por la vuelta al trabajo y 110 [36 \%] por la continuación de la huelga" (en "La vuelta de los carreros al trabajo", La Vanguardia, XVIII, 1796, 26/1/1912, p. 2).

71 “Obreros del puerto”, La Vanguardia, XVIII, 1797, 27/1/1912, p. 2. 
72 “Obreros del puerto", La Protesta, XV, 1923, 30/1/1912, p. 2.

73 "La huelga del puerto, barracas de lana, mercado de frutos y carreros", La Acción Obrera, VII, 217, 3/2/1912, p. 1.

74 "El paro en el puerto", La Nación, XLIII, 14583, 13/1/1912, p. 10 y “Obreros del Puerto y Conductores de Carros", La Vanguardia, XVIII, 1790, 19/1/1912, p. 1.

75 "Una comisión de obreros del puerto conferenció ayer con el ministro del interior, a quien expuso los motivos en que fundaban los huelguistas su petición de mejoras”, en "El paro en el puerto”, La Nación, XLIII, 14584, 14/1/1912, p. 10. "Ayer estuvo en el ministerio del interior una comisión de los obreros del puerto", "Obreros del Puerto y Conductores de Carros", La Vanguardia, XVIII, 1787, 16/1/1912, p. 1. "Los delegados de los huelguistas acompañados por el doctor Cesar Viale, concurrieron ayer al ministerio”, de la reunión participaron, además del ministro, el presidente del DNT y el jefe de policía, ver "El paro en el puerto: las gestiones de arreglo", La Nación, XLIII, 14596, 26/1/1912, p. 10.

76 “Marineros y foguistas”, La Vanguardia, XVIII, 1798, 28/1/1912, p. 2.

77 “Marineros y foguistas", La Vanguardia, XVIII, 1809, 10/2/1912, p. 2.

78 "Obreros del puerto", La Protesta, XV, 1923, 30/1/1912, p. 2.

79 “La huelga de maquinistas y fogoneros: su terminación”, La Nación, XLIII, 14627, 26/2/1912, p. 13. El acta-acuerdo decía: "Readmisión gradual del personal en huelga en su situación anterior al conflicto, bajo la garantía de equidad y justicia que resulta de la intervención del excelentísimo señor presidente de la nación, para llegar así a la normalización real del servicio a base de personal competente e idóneo".

80 "Fin de la huelga ferroviaria", La Acción Obrera, VII, 221, 2/3/1912, p. 1.

81 "La última lucha, que cierra, puede decirse, la era de las grandes luchas del año obrero, fue la famosísima e ilustrativa huelga del numeroso personal de tracción de los ferrocarriles (maquinistas y foguistas de locomotoras)", en "Las grandes huelgas del puerto y otros conflictos”, La Confederación, II, 13, 1/5/1912, p. 3.

82 La FORA denunciaba la represión que padecía la clase obrera en aquel período, advertía que "por todas partes y en todos los lugares de la república se están cometiendo verdaderos crímenes con los trabajadores” y "el terror entre las familias de los obreros sindicados como conscientes y revolucionarios”, en "Al proletariado", Organización Obrera: órgano de la Federación Obrera Regional Argentina, 1/7/1912.

83 "Cuarto Congreso de la FOA", La Protesta, VIII, 363, 3/8/1904, p. 3. Un año antes, en el tercer congreso, se había aprobado la siguiente declaración: "la Federación Obrera no elevará jamás petición alguna a los poderes públicos" (en “Tercer Congreso de la Federación Obrera Argentina”, La Protesta, VII, 217, 14/6/1903, p. 4).

84 "Acuerdos industriales y arbitraje", Boletín del Departamento Nacional del Trabajo, n ${ }^{\circ}$ 1, 30/6/1907, p. 42. La propuesta del DNT no suscitó ningún debate dentro de la UGT, se rechazó de manera inmediata y por unanimidad. La nota fue redactada por Lucas Tortorelli y aprobada el 13/5/1907 (ver Libro de Actas de la UGT, pp. 76 y 79 ).

85 El caso más resonante fue la entrevista de una delegación de la FORA con el ministro del interior, José Gálvez, efectuada el 7 de mayo de 1910. Cuando se retiraban, los delegados obreros manifestaron "que ellos no eran partidarios del desorden ni de temperamentos radicales, sino que solo deseaban el bienestar de los del gremio y la felicidad de los compañeros" (en "Petición de la Federación Obrera: entrevista de delegados con el ministro del interior", La Nación, XLI, 13081, 8/5/1910, p. 8).

86 En ese sentido, la huelga general más importante fue la de enero de 1907, convocada en solidaridad con el gremio del rodado de la ciudad de Rosario (Belkin, 2015).

87 En 1909 se realizó una huelga general en repudio al asesinato del pedagogo libertario Francisco Ferrer (Belkin, 2019).

88 "Movimiento Obrero", La Protesta, XIV, 1917, 19/12/1912, p. 4.

89 “Movimiento Obrero", La Protesta, XIV, 1923, 30/1/1912, p. 2. 